\title{
Correction: The World Health Organization Fetal Growth Charts: A Multinational Longitudinal Study of Ultrasound Biometric Measurements and Estimated Fetal Weight
}

Torvid Kiserud, Gilda Piaggio, Guillermo Carroli, Mariana Widmer, José Carvalho, Lisa Neerup Jensen, Daniel Giordano, José Guilherme Cecatti, Hany Abdel Aleem, Sameera A. Talegawkar, Alexandra Benachi, Anke Diemert, Antoinette Tshefu Kitoto, Jadsada Thinkhamrop, Pisake Lumbiganon, Ann Tabor, Alka Kriplani, Rogelio Gonzalez Perez, Kurt Hecher, Mark A. Hanson, A. Metin Gülmezoglu, Lawrence D. Platt

The title and caption of Table 12 does not correspond to the table content. The correct title and caption is: "Table 12. Growth chart for fetal femur length/biparietal diameter ratio."

The title and caption of Table 12 does not correspond to the table content. The correct title and caption is: "Table 13. Growth chart for fetal femur length/head circumference ratio."

\section{Reference}

1. Kiserud T, Piaggio G, Carroli G, Widmer M, Carvalho J, Neerup Jensen L, et al. (2017) The World Health Organization Fetal Growth Charts: A Multinational Longitudinal Study of Ultrasound Biometric Measurements and Estimated Fetal Weight. PLoS Med 14(1): e1002220. https://doi.org/10.1371/ journal.pmed.1002220 PMID: 28118360

\section{G open AcCess}

Citation: Kiserud T, Piaggio G, Carroli G, Widmer M, Carvalho J, Jensen LN, et al. (2021) Correction: The World Health Organization Fetal Growth Charts: A Multinational Longitudinal Study of Ultrasound Biometric Measurements and Estimated Fetal Weight. PLoS Med 18(1): e1003526. https://doi.org/10.1371/journal. pmed. 1003526

Published: January 7, 2021

Copyright: ๑ 2021 Kiserud et al. This is an open access article distributed under the terms of the Creative Commons Attribution License, which permits unrestricted use, distribution, and reproduction in any medium, provided the original author and source are credited. 